\title{
RELATORIO \\ RELATIVO AO ANNO LECTIVO DE 1927
}

\section{Illmo. Exmo. Snr.}

Cumprindo o disposto na letra i) do art. 114, do decreto n. 11.530, de 18 de Março de 1915, letra j) do art. 199 , do decreto n. 16.782-A, de 13 de Janeiro de 1925 , n. XVII, do art. 9. ${ }^{\circ}$ do antigo Regimento Interno desta Faculdade e n. XVI, do art. $8 .^{\circ}$ do actual Regimento Interno, passo a fazer o relatorio minucioso de tudo quanto occorreu, neste estabelecimento, a respeito da disciplina, ordem, serviço militar, observancia das leis e do orçamento, no anno lectivo findo de 1927.

\section{ABERTURA DOS TRABALHOS}

$\mathrm{Na}$ fórma do disposto nos arts. 74 do decreto $\mathrm{n}$. 11.530 , de 1915 e 202 do dec. n. 16.782-A, de 1925, citados, e 143 do Regimento Interno então em vigor, os trabalhos deste instituto de ensino foram abertos no dia 7 de Janeiro, celebrando a Congregação, nesse dia, a sua primeira reunião, nos termos do art. $1 .^{\circ}$ do dec. n. 5.121, de 29 de Dezembro de 1926, que antecipou o curso do $5 .^{\circ}$ anno.

\section{PRESENÇA DOS PROFESSORES}

Nessa primeira reunião da Contigregação, realizada a 7 de Janeiro, foi verificado que se achavam promptos para o serviço os professores Drs. Candido Nazianzeno Nogueira da Motta, João Braz de Oliveira Arruda, Luiz Bar- 
bosa da Gama Cerqueira, Raphael Corrêa de Sampaio, Manoel Pacheco Prates, Theophilo Benedicto de Souza Carvalho, José Augusto Cezar, José Joaquim Cardoso de Mello Neto, Spencer Vampré; Octavio Mendes, Braz de Sousa Arruda e os docentes livres, que regiam cadeiras, Drs. Gabriel José Rodrigues de Rezende Filho, Waldemar Martins Ferreira e Antonio de Sampaio Doria.

\section{EXAME VESTIBULAR}

$\mathrm{Na}$ fórma do disposto no art. 62 do Regimento Interno, então em vigor, a inscripção para o exame vestibular, instituido pelo decr. n. 11.530, de 1915 e dos arts. 206 e 215 do dec. 16.782-A, de 1925, como indispensavel para a matricula nesta Faculdade, aberta a 3 de Março e encerrada a 12 desse mesmo mez e, reaberta a 18 e encerrada a 28 do msmo mez, ex-vi do telegramma de 16 desse mez, do Director Geral do Departamento Nacional do Ensino, concorreram 169 condidatos. O exame iniciou-se com a prova escripta no dia 19 de Março, terminando no dia 25 de Abril, tendo sido approvados 165 e reprovados 4 candidatos (Annexo II)

A commissão julgadora desse exame foi constituida, na primeira inscripção, pelos professores Drs. Raphael Corrêa de Sampaio, Manoel Pacheco Prates, Theophilo Benedicto del Souza Carvalho e Frandisco Antonio de Almeida Morato, e, na 2." inscripção, pelos mesmos professores, sendo o Dr. Francisco A. A. Morato substituido pelo docente livre Dr. Antonio de Sampaio Doria, e, sendo a mesma commissão sempre presidida pelo Dr. Antonio Amancio Pereira de Carvalho, professor mais antigo e em disponibilidade, na falta de vice-Director, ainda não nomeado.

\section{HORARIO DAS AULAS}

Pela Congregação dos professores, na fórma do disposto na letra $\mathrm{k}$ ) do art. 199 do citado dec. 16.782-A, de 1925, foi adoptado o horario das aulas, constante do Annexo I. 


\section{PROGRAMMAS DE ENSINO}

Adoptados pelos professores das cadeiras dos cursos, foi nomeada uma commissão composta dos Drs. Candido N. N. da Motta, Manoel Pacheco Prates e Spencer Vampré, para dar parecer sobre os programmas do 5. anno, cujo curso fôra antecipado, e dos Drs. Manoel Pacheco Prates, Theophilo B. de Souza Carvalho e Francisco A. de A. Morato, sobre os quatro annos restantes do curso, tendo essas commissões formulado os respectivos pareceres, que foram approvados pela Congregação, os do $5 .^{\circ}$ anno, em sessão de 7 de Janeiro e os dos outros annos, em sessão de 2 de Março. Os programmas foram impressos e postos á venda na Thesouraria da Faculdade.

\section{REPRESENTANTE DA CONGREGAÇÃO JUNTO AO DEPARTAMENTO NACIONAL DO ENSINO}

A Congregação dos professores, em sessão de 2 de Março, na fórma do disposto na letra b) do art. 14 do citado dec. 16782-A, de 1925, reelegeu, por unanimidade de votos, o cathedratico em disponibilidade Dr. Reynaldo Porchat, como seu representante, junto ao Conselho do Ensino Secundario e do Superior do Departamento Nacional do Ensino.

\section{DESIGNAÇÃO DE PROFESSORES}

No correr do anno lectivo findo, foram designados O Bacharel Gabriel José Rodrigues de Rezende Filho, docente livre, para reger a $1 .^{a}$ cadeira do $5 .^{\circ}$ anno, que estava vaga, com o fallecimento do Dr. Estevam de Araujo Almeida e a $4 .^{\text {. }}$ cadeira do $4 .^{\circ}$ anno, em substituição ao Dr. Francisco Antonio de Almeida Morato, durante o tempo, em que este professor esteve com assento no Congresso Nacional; o Bacharel Laurentino Antonio Moreira de Azevedo, docente livre, para reger a $1 .^{a}$ cadeira do $5 .{ }^{\circ}$ anno, que estava vaga, com o fallecimento do Dr. Estevam de Araujo Almeida, e durante o tempo, em que o docente 
livre Bacharel Gabriel José Rodrigues de Rezende Filho, esteve impedido nas sessões do Conselho do Ensino Secundario e do Superior, junto ao Departamento Nacional do Ensino; o Bacharel Waldemar Martins Ferreira, docente livre, para reger a $1 .^{\prime \prime}$ cadeira do $3 .^{\circ}$ anno, que vagou com o fallecimento do Dr. Frederico Vergueiro Steidel; o Bacharel Antonio de Sampaio Doria, docente livre, para reger a $1 .^{\text {a }}$ cadeira do 1. " anno, que estava vaga com a disponibilidade do Dr Uladislau Herculano de Freitas, - Dr. Raphael Corrêa de Sampaio, cathledratico, para reger a $2 .^{\prime}$ cadeira do 5. anno, que vagou com a aposentadoria do Dr. José Manoel de Azevedo Marques, a 3." cadeira do 5. anno, em substituição ao Dr. José de Alcantara Machado d'Oliveira, que estava em commissão do Ministerio da Justiça e Negocios Interiores, a $4 .^{a}$ cadeira do $4 .^{\circ}$ anno, em substituição ao Dr. Francisco de Almeida Morato, que estava com assento no Congresso

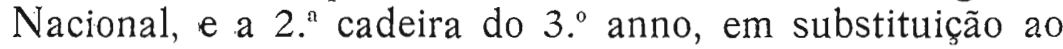
Dr. Candido Nazianzeno Nogueira da Motta, que estava no gozo de licença; o Dr. Manoel Pacheco Prates, cathedratico, para reger a 3." cadeira do $4 .^{\circ}$ anno, que estava vaga, com a disponibilidade do Dr. Antonio Januario Pinto Ferraz; o Dr. Candido Nazianzeno Nogueira da Motta, cathedratico, para reger a $2 .^{\circ}$ cadeira do $4 .^{\circ}$ anno, em substituição do Dr. Luiz Barbosa da Gama Cerqueira, que estava no gozo de licença; e o Dr. Theophilo Benedicto de Souza Carvalho, cathedratico, para reger a cadeira de Direito Administrativo, em substituição ao $\mathrm{Dr}$ Manoel Pedro Villaboim, que estava com assento no Congresso Nacional.

\section{INSCRIPÇÃO PARA EXAMES DA SEGUNDA EPOCA}

Para os exames da $2:^{a}$ epoca, inscreveram-se 89 alumnos, sendo no $1 .^{\circ}$ anno-20, no $2 .^{\circ}-21$, no $3 .^{\circ}-17$ no $4 .^{\circ}-18$ e no $5^{\circ}-13$. O resultado desses exames, consta do Annexo II. 


\section{INSCRIPÇÃO DA MATRICULA}

Matricularam-se nos cinco annos do curso, 500 alumnos, sendo no $10^{\circ}$ anno -181 , no $2 .^{\circ}-112$, no $3 .^{\circ} 179$, no $4 .^{\circ}-58$ e no 5. -70 , como consta do Annexo XI (impresso)

\section{TRANSFERENCIA DE MATRICULA}

Durante o periodo das ferias, quatro alumnos requereram guia de transferencia, sendo 2 do primeiro anno e 1 do $3 .^{\circ}$ anno, para a Faculdade de Direito da Universidade do Rio de Janeiro e 1 do i "anno para a Faculdade Livre de Direito de Nictheroy.

\section{LICENÇA}

No correr do anno lectivo findo, estiveram no gozo de licença: o Dr. Manoel Pedro Villaboim, cathedratico de Direito Administrativo, de 22 de Janeiro a 17 de Abril; - Dr. Candido Nazianzeno Nogueira da Motta, cathedratico da 2." cadeira do 3. anno, de 15 a 27 de Setembro e o Dr. Luiz Barbosa da Gama Cerqueira, cathedratico da $2 .^{. ~ c a d e i r a ~ d o ~} 4 .^{\circ}$ anno, de 12 de Maio a 10 de Junho.

\section{SERVIÇO PUBLICO}

Durante o anno lectivo findo, estiveram ausentes da Faculdade, por motivo de serviço publico o Dr. José de Alcantara Machado d'Oliveira, cathedratico da 3." cadeira do $5 .^{\circ}$ anno, de $1 .^{\circ}$ de Janeiro 9 de Fevereiro, por ter estado em commissão do Ministerio da Justiça e Negocios Interiores; e de 16 de Julho a 9 de Agosto, por ter estado no Departamento Nacional do Ensino, como representante desta Faculdade; o Dr. Manoel Pedro Villaboim, cathedratico, de 18 de Abril a 31 de Dezembro, por estar com assento no Congresso Nacional, como Deputado por São Paulo; o Dr. Reynaldo Porchat, cathedratico em disponibilidade, de 16 de Julho a 9 de Agosto, por ter estado no Departamento Nacional do Ensino, como representante desta 
Faculdade; e o Dr. Francisco Antonio de Almeida Morato, cathedratico da $4 .^{\text {" }}$ cadeira do $4 .^{\circ}$ anno, de 18 de Abril a 31 de Dezembro, por ter estado com assento no Congresso Nacional, como Deputado por São Paulo.

\section{SUBSTITUIÇÕES}

No correr do anno lectivo findo, o Dr. Candido Nazianzeno Nogueira da Motta, cathedratico, de 12 de Maio a $1 .^{\circ}$ de Julho, regeu a $2 .^{a}$ cadeira do $4 .^{\circ}$ anno, em substituição ao Dr. Luiz Barbosa da Gama Cerqueira; o Dr. Raphael Corrêa de Sampaio, cathedratico, de 1. $0^{\circ}$ de Janeiro a 31 de Dezembro, regeu a $2 .^{2}$ cadeira do $5 .^{\circ}$ anno, que estava vaga, com a aposentadoria do Dr. José Manoel de Azevedo Marques, de $1 .^{\circ}$ de Janeiro a 9 de Fevrreiro, tambem regeu a $3 .^{\circ}$ cadeira do $5 .^{\circ}$ anno, em substituição ao Dr. José de Alcantara Machado d'Oliveira; de 22 de Abril a 15 de Agosto, tambem regeu a 4." cadeira do 4. ${ }^{\circ}$ anno, em substituição ao Dr. Francisco Antonio de Almeida Morato, e de 15 a 27 de Setembro regeu ainda a $2 .^{a}$ cadeira do $3 .^{\circ}$ anno, em substituição ao Dr. Candido Nazianzeno Nogueira da Motta, o Dr. Manoel Pacheco Prates, cathedratico, de $10^{\circ}$ de Janeiro a 14 de Julho, regeu a cadeira de Direito Civil, que estava vaga, com a disponibilidade do Dr. Antonio Januario Pinto Ferraz; - Dr. Theophilo Beriedicto de Souza Carvalho, cathedratico, de $1 .^{\circ}$ de Janeiro a 31 de Dezembro, regeu a cadeira de Direito Administrativo, em substituição ao Dr Manoel Pedro Villaboim; o Dr. Gabriel José Rodrigues de Rezende ${ }^{\circ}$ Filho, docente livre, de $1 .^{\circ}$ de Janeiro a 17 de Fevereiro, e, de 16 de Março a 31 de Dezembro, regeu a $1 .^{\text {. }}$ cadeira do $5 .^{\circ}$ anno, que estava vaga com o fallecimento do Dr. Estevam de Araujo Almeida, e de 16 de Agosto a 31 de Dezembro ainda regeu a $4 .^{\text {. }}$ cadeira do 4..$^{\circ}$ anno, em substituição ao Dr. Francisco Antonio de Almeida Morato; o Dr. Laurentino Antonio Moreira de Azevedo, docente livre, de 21 de Fevereiro a 15 de Março, regeu a $1 .^{a}$ cadeira do $5^{\circ}$ anno, que estava vaga com o 
fallecimento do Dr. Estevam de Araujo Almeida, o Dr. Waldemar Martins Ferreira docente livre, de $10^{\circ}$ de Janeiro a 2 de Novembro, regeu a $1 .^{n}$ cadeira do $4 .^{\circ}$ anno, que estava vaga com o fallecimento do Dr. Frederico Steidel, e o Dr. Antonio de Sampaio Doria, docente livre, de $1^{\circ}$ de

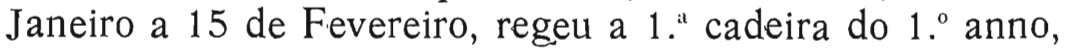
que estava vaga com a disponibilidade do Dr. Uladislau Herculano de Freitas.

\section{COMMISSÕES AUXILIARES DO DIRECTOR}

$\mathrm{Na}$ sessão ordinaria da Congregação, realizada a 2 de Março, foram eleitos os cathedraticos Drs. João Braz de Oliveira Arruda, José Joaquim Cardozo de Mello Neto e Spencer Vampré, para a commissão de ensino; Drs. Raphael Corrêa de Sampaio, Theophilo Benedicto de Souza Carvalho e Francisco Antonio de Almeida Morato, para a de docencia, e Drs. Manoel Pacheco Prates, Braz de Sousa Arruda e Francisco Antonio de Almeida Morato, para a de redaç̧ão de publicações.

\section{NOMEAÇÃO E POSSE DE VICE- DIRECTOR}

O Dr. José de Alcantara Machado d'Oliveira, professor cathedratico, nomeado vice-Director, por decreto de 20 de Junho, tomou posse e entrou no exercicio desse cargo, no dia 15 de Julho seguinte.

\section{CONCURSOS DE PROFESSORES CATHEDRATICOS}

Conforme editaes publicados, foram abertas pelo prazo de seis mezes, e iniciadas, findos os prazos, as inscripções para o preenchimento dos logares vagos de professores cathedraticos de Direito Civil e de Direito Commercial, a da 1." inscripção que fôra aberta a 17 de Abril de 1926 e encerrada a 18 de Outubro do mesmo anno, concorreram os tres candidatos - Bachareis Jorge Americano, Vicente Ráo e Aureliano Candido de Oliveira Gui- 
marães, cujas inscripções haviam sido approvadas pela Congregação, em sessão de 22 de Novembro de 1926, e á de Direito Commercial, que fôra aberta a $1^{\circ}$ de Dezembro de 1926 e encerrada a $1 .^{\circ}$ de Junho de 1927 , concorreu um unico candidato - Bacharel Waldemar Martins Ferreira, docente livre dessa disciplina e cuja inscripção foi approvada pela Congregação em sessão de 9 de Junho de 1927

As provas do concurso para o preenchimento do logar de professor cathedratico de Direito Civil, a que se submetteram os tres unicos candidatos, julgados legalmente habilitados e aptos para esse concurso, tiveram inicio no dia 30 de Maio e terminaram no dia 7 de Junho, dia, em que, em sessão publica, se ralizou o julgamento que deu o resultado seguinte: Bacharel Vicente Ráo, com a media final de nove e setenta e cinco centesimos $(9,75)$, o Bacharel Jorge Americano, com a media final de sete e oito decimos $(7,8)$, e o Bacharel Aureliano Candido de Oliveira Guimarães, com a media final de tres e quatro decimos $(3,4)$, tendo sido, na sessão da Congregação de 9 de Junho assignado o officio da communicação ao Governo do nome do Bacharel Vicente Ráo, candidato habilitado, no mesmo concurso, para o provimento ao logar de professor cathedratico de Direito Civil.

As provas do concurso para o preenchimento do logar de professor cathedratico de Direito Commercial, a que se submetteu o unico candidato inscripto e legalmente habilitado e apto para esse concurso, tiveram inicio no dia 2 de Agosto e terminaram no dia 5 desse mez, dia em que, em sessão publica, se realizou o julgamento, que deu o resultado seguinte: Bacharel Waldemar Martins Ferreira, com a media final de nove e setenta e tres centesimos $(9,73)$, tendo sido, em sessão da Congregação, do dia 6 do mesmo mez, assignado o officio de communicação ao Governo o nome do mesmo Bacharel Waldemar Martins Ferreira, habilitado no mesmo concurso, para o provimento ao logar de professor cathedratico de Direito Commercial. 


\section{NOMEAÇÃO E POSSE DO. VICE-DIRECTOR}

O Dr. José de Alcantara Machado d'Oliveira, cathedratico desta Faculdade, nomeado vice-Director, por decreto de 20 de Junho, tomou posse a 15 de Julho seguinte, tendo entrado no exercicio desse cargo, nessa mesma data.

\section{NOMEAÇÕES E POSSES DE PROFESSORES}

\section{CATHEDRATICOS}

O Dr. Antonio de Sampaio Doria, docente livre de Direito Constitucional, nomeado professor cathedratico de Direito Constitucional, por decreto de 8 de Fevereiro, tomou posse desse cargo no dia 16 desse mesmo mez, data, em que entrou em exercicio desse cargo; o Dr. Vicente Ráo, nomeado professor cathedratico de Direito Civil, por decreto de 4 de Julho, tomou posse desse cargo no dia 15 desse mesmo mez, tendo, nesse mesmo dia, entrado no exercicio desse cargo, e o Dr. Waldemar Martins Ferreira, docente livre de Direito Commercial, nomeado professor cathedratico de Direito Commercial, por decreto de 24 de Outubro, tomou posse no dia 3 de Novembro seguinte, tendo, nesse mesmo dia, entrado no exercicio desse cargo.

\section{DOCENCIA LIVRE}

$\mathrm{Na}$ fórma do disposto no art. 179 do decr. n. 16.782-A, de 1925, annunciada e encerrada a inscripção para a docencia livre, á ella concorreram os Drs. Antonio Ferreira de Almeida Junior e Armando de Souza Diniz para a cadeira de Medicina Publica; o Bacharel Sebastião Pacheco Jordão, para a de Direito Publico Internacional; os Bachareis Mario Mazagão e Hermes Lima, para a de Direito Administrativo e Sciencia da Administração; - Bacharel Raul Renato Cardoso de Mello Tucunduva, para a de Direito Judiciario Civil; o Bacharel Ernesto de Moraes Leme, para a de Direito Commercial; o Bacharel Noé Azevedo, para a de Direito Penal, e os Bachareis Ernesto de Moraes Leme e Carlos de Moraes Andrade para a de Direito Civil. 
A Congregação dos professores, em sessão realizada a 4 de Outubro resolveu, por proposta do Dr. José de Alcantara Machado d'Oliveira, que foi approvada por unanimidade de votos, que a Congregação representasse ao Governo da Republica, no sentido de ser adiado, sine die, o concurso da docencia livre. Tendo o Ministerio da Justiça e Negocios Interiores, por despacho de 21 de Outubro, mandado proseguir nas provas desse concurso, a Congregação, em sessão realizada a 7 de Novembro, tomando conhecimento dessas inscripções, resolveu, mediante parecer da respectiva commissão de docencia, o qual foi approvado, indeferir o requerimento do Bacharel Sebastião $\mathrm{Pa}$ checo Jordão, inscripto para a cadeira de Direito Publico Internacional, por ter mais de quarenta annos, sendo assim, approvadas as inscripções dos demais candidatos. Nessa mesma reunião de 7 de Novembro, foram eleitos para compor as commissões de arguição dos concursos de docencia livre, alem dos professores da respectiva cadeira, foram eleitos, para a de Medicina Publica, os professores Drs. Antonio Amancio Pereira de Carvalho, Raphael Corrêa de Sampaio e Vicente Ráo, e, para supplentes, os professores Drs. João Braz de Oliveira Arruda e Manoel Pacheco Prates, para a de Direito Administrativo, os professores Drs. José Joaquim Cardozo de Mello Neto, Waldemar Martins Ferreira e, para supplentes, os professores Drs. José de Alcantara Machado d'Oliveira e Vicente Ráo; para a de Direito Judiciario Civil, os professores Drs. Luiz Barbosa da Gama Cerqueira, Raphael Corrêa de Sampaio, Vicente Ráo e Manoel Pacheco Prates, e, para supplentes, os professores Drs. Theophilo Benedicto de Souza Carvatho e Waldemar Martins Ferreira, para a de Direito Civil, os professores Drs. José Ulpiano Pinto de Souza e para supplentes os professores Drs. João Braz de Oliveira Arruda e Waldemar Martins Ferreira, para a de Direito Commercial, os professores Drs. João Braz de Oliveira Arruda e Raphael Corrêa de Sampaio, e, para supplentes os professores Drs. José Joaquim Cardozo de Mello Neto e Vi- 
cente Ráo; e, para a de Direito Penal, os professores Drs. Raphael Corrêa de Sampaio e Braz de Sousa Arruda, e, para supplentes os professores Drs. Theophilo Benedicto de Souza Carvalho e Spencer Vampré. A Congregação, attendendo a que os exames da primeira epoca se approximavam e, depois de terminados estes, começava o periodo das ferias escolares, resolveu adiar sine diæ, a realização da primeira prova desses concuros para o proximo anno escolar.

\section{NOMEAÇÃO E POSSE DE DOCENTE LIVRE}

Por portaria de $1 .^{\circ}$ de Agosto, foi nomeado o Bacharel Herme Lima, pelo prazo de dez annos, docente livre de Direito Constitucional, nos termos dos arts. 176 e 199, letra c) do dec. n. 16.782-A, de 13 de Janeiro de 1925 , e arts. $8^{\circ}$ n. IX, e 39 do Regimento Interno desta Faculdade attendendo ás habilitações, qule demonstrou, no concurso, a que se procedeu, nesta Faculdade, de 17 a 23 de Dezembro de 1926.

\section{INSCRIPÇÃO PARA EXAME DE PRIMEIRA EPOCA}

Para os exames da primeira epoca, inscreveram-se 443 alumnos, sendo no $1 .^{\circ}$ anno, 167 , no $2 .^{\circ}-100$, no $3 .^{\circ}-$ 62 , no $4 .^{\circ}-47$ e, no $5 .^{\circ}-67$. O resultado desses exames consta do Annexo II.

Nos termos do disposto nos $\delta \oint 1 .^{\circ}$ e $2 .^{\circ}$ do dec. $n$. 5.121 , de 29 de Dezembro de 1926, que antecipou o curso do $5 .^{\circ}$ anno, os exames do referido $5 .^{\circ}$ anno, foram prestados, em Julho.

\section{COLLAÇÃO DE GRAUS}

No dia 11 de Agosto do anno findo, foi collado o grau de Bacharel em Sciencias Juridicas e Sociaes a 76 bacharelandos, os quaes são naturaes dos seguintes Estados; São Paulo 68, Minas Geraes 3, Matto-Grosso 1, Bahia 1, Amazonas 1, Pernambuco 1, e Paraná 1. (Annexo III). 
Durante o anno, foi collado o grau de Doutor em Sciencias Juridicas e Sociaes a tres :Bachareis, que foram nomeados professores cathedraticos desta Faculdade, sendo, dois naturaes do Estado de São Paulo e um do Estado de Alagôas.

\section{CARTAS DE DOUTORES}

No correr do anno lectivo findo, foram expedidas tres Cartas de Doutor em Sciencias Juridicas e Sociaes, a egual numero de Doutores formados por esta Faculdade e que receberam o grau de Doutor sendo naturaes dois do Estado de São Paulo e um do Estado: de Alagôas.

\section{CARTAS DE BACHAREL}

No correr do anno findo, foram expedidas 89 Cartas de Bacharel a egual numero de Bachareis formados por esta Faculdade em Sciencias Juridicas e Sociaes, os quaes são naturaes dos seguintes Estados, São Paulo-77, Minas Geraes 5, Rio Grande do Sul 1, Matto-Grosso 1, Pernambuco 1, Paraná 1, Bahia 1, Amazonas 1, e Ceará 1, (Annexo IV).

\section{EXAME DE PROFISSIONAL DIPLOMADO NO EXTRANGEIRO}

O unico candidato - Antonio Ruffolo diplomado em Jurisprudencia pela Real Universidade de Roma, inscripto para a revalidação do seu diploma, a 26 de Outubro de 1926, foi submettido ao respectivo exame no dia 29 de Dezembro de 1927, tendo sido inhabilitado por cinco votos.

\section{SERVIÇO MILITAR}

De conformidade com a informação prestada pelo Instructor Militar, durante o anno findo, apenas 13 alumnos desta Faculdade frequentaram a instrucção militar, dos quaes foram approvados 12 e reprovado 1 . 


\section{SESSÕES DA CONGREGAÇÃO}

Durante o anno lectivo findo, a Congregação dos Professores desta Faculdade celebrou dezesete (17). sessões, sendo quinze (15) ordinarias e duas (2) extraordinarias, nas quaes foram tratados diversos assumptos.

\section{PROCEDIMENTO DOS ALUMNOS}

O procedimento dos alumnos durante o anno lectivo findo, foi bom, nada tendo occorrido digno de menção.

\section{BIBLIOTHECA}

A Bibliotheca desta Faculdade, durange o anno findo, foi frequentada por 4.629 pessoas, que consultaram 1.592 obras, em 2.890 volumes, sendo: em portuguez 1.147 , em francez 260, em italiano 91, em hespanhol 57, em inglez 18 , em latim 17, em allemão 2 , estando no numero dos consulentes 1.964 pessôas, que leram jornaes e revistas. deveres.

Os empregados da Bibliotheca bem cumpriram o seus

\section{THESOURARIA}

O balanço da Thesouraria desta Faculdade, constante do Annexo VI, e fechado a 4 de Janeiro findo, accusa que ha um saldo de setecentos e cincoenta e um contos oitocentos e trinta e seis mil trezentos réis $(751: 836 \$ 300)$, assim distribuido: No Banco do Commercio e Industria, trinta e cinco contos seiscentos e onze mil e cem réis $(35: 611 \$ 100)$, no Banco do Brasil, trinta contos duzentos e vinte e cinco mil duzentos réis $(30: 225 \$ 200)$ e seiscentos e oitenta e seis contos de réis $(686: 000 \$ 000)$ importancia de 686 apolices da União, do valor de um conto de réis $(1: 000 \$ 000)$ cada uma, ao juro de cinco por cento (5\%) a.o anno. 
O saldo apurado em 1926, foi de seiscentos e noventa e dois contos duzentos e sessenta e quatro mil novecentos réis $(692: 264 \$ 900)$ havendo, portanto, um excesso de cincoenta e nove contos quinhentos e setenta e um mil e quatrocentos réis $(59: 571 \$ 400)$.

O Thesoureiro bem cumprio os seus deveres.

\section{SECRETARIA}

Os serviços da Secretaria estiveram sempre em dia, tendo os empregados bem cumprido os seus deveres.

Secretaria da Faculdade de Direito de

São Paulo, em 25 de Fevereiro de 1928.

O Director:
(a)
A. J. Pinto Ferraz. 